\title{
O INTUICIONISMO MORAL E OS DILEMAS MORAIS
}

\author{
Ricardo Bins Di Napoli \\ Universidade Federal de Santa Maria
}

\begin{abstract}
In the history of moral philosophy, from Plato, to Aristotle, I. Kant, J. Stuart Mill, and more recently including rationalists like J. Habermas, J. Rawls, R. M. Hare and C. Korsgaard, several attempts have been made to show that reason is the best guide to our moral actions and judgements. On the other hand, some philosophers like D. Hume, A. Smith, A. J. Ayer, P. F. Strawson, and S. Blackburn have taught that morality must be a task of our moral sentiments. I think it is more plausible to accept that both of our capacities must be considered in moral decision-making, because there are important new data from psychology, the cognitive sciences and neurosciences that provide evidence for the importance of emotions in our decisions, not just rationality. Moral laws, moral values and moral sentiments might all give us good reasons to act morally. This is the reason, why I support the view that moral philosophy accounts fail to offer a good way to treat ethical issues when they do not also consider the importance of emotions. From this point of view, I intend to show here that one form of intuitionism can help us to answer the question about moral knowledge and to grasp the way in which we decide. I argue that this form of intuitionism should be able to help us to deal with moral dilemmas. In the first section of this article, I consider the definitions of moral dilemmas, then, in the second, third, and fourth sections I explain three forms of intuitionism - the rationalist (D. Ross), the empiricist (R. Audi), and the reflexive (C. Gowans) - and finally in the last section I point out a new way of thinking about our intuitions. I will call this form naturalistic intuitionism. Moral naturalism is the assumption that our decisions or judgements are partially determined by a natural process and natural properties of the world. In this sense I assume that some of our emotional capacities (like the ability to feel disgust, outrage, indignation, regret, shame, etc), or cognitive capacities (e.g. rationality, cognition) are hardwired into our psychology. This means that social moral rules are learned from childhood, although given by evolution. Hence, they can be taken as natural in the sense that they are the product both of the social world and of the biological constitution of the human being.
\end{abstract}

Keywords: Moral Intuitionism, moral dilemmas, moral rationalism, moral sentimentalism, ethics. 
Resumo: Na história da filosofia moral, por um lado, de Platão, passando por Aristoteles, I. Kant, J. S. Mill, e mais recentemente incluindo racionalistas como J. Habermas, J. Rawls, R. M. Hare e $C$. Korsgaard, várias tentativas foram feitas para mostrar que a razão é o melhor guia para nossas ações e julgamentos. Por outro lado, outros filósofos como D. Hume, A. Smith, A. J. Ayer, P. F. Strawson and S. Blackburn ensinaram que a moralidade deve ser uma tarefa para nossos sentimentos. Eu penso que é mais plausível aceitar que nossas duas capacidades devem ser consideradas na decisão moral, porque há novos importantes dados da psicologia, ciências cognitivas e neurociências que evidenciam a importância dos sentimentos nas nossas decisões, e não apenas a da racionalidade. Leis, valores e sentimentos morais podem todos nos dar boas razões para agirmos moralmente. Esta é a razão pela qual eu defendo aqui a visão que as abordagens da filosofia moral falham em oferecer uma boa maneira de tratar questões morais quando elas não abordam também 0 papel das emoções. Deste ponto de vista, eu pretendo mostrar aqui que uma forma de intuicionismo pode ajudar-nos a responder a questão sobre o conhecimento moral e aprender o modo como nós decidimos. Eu argumento que esta forma de intuicionismo pode nos ajudar a lidar com os dilemas morais. Na primeira parte do artigo eu considero as definições de dilemas morais, na segunda, na terceira e quarta partes eu explico três formas de intuicionismo - a racionista (D. Ross), a empirista (R. Audi) e a reflexiva (C. Gowans) - e finalmente na última secção eu indico uma forma de pensar as intuições. Eu chamo este tipo de intuicionismo naturalista. O naturalismo moral é a posição que nossas decisões e julgamentos são parcialmente determinados por um processo natural e propriedades naturais do mundo. Neste sentido, eu assumo que algumas de nossas capacidades emotivas (como a de sentir nojo, revolta por desaprovação, indignação, arrependimento, vergonha, etc.) ou capacidades cognitivas (e.g. racionalidade, cognição) estão gravadas e integradas na nossa psicologia. Isto significa que as normas morais sociais são aprendidas deste a infância, embora dadas pela evolução. Logo, elas podem ser tomadas como naturais no sentido que elas são produtos tanto do mundo social como da constituição biológica do ser humano.

Palavras-chave: Intuitionismo moral, dilemas morais, moral, racionalismo moral, sentimentalismo moral, ética.

\begin{abstract}
"Extingam-se todos os sentimentos vívidos (warm) e propensões em favor da virtude e toda repugnância ou aversão ao vício, torne-se cada homem totalmente indiferente diante dessas distinções, e a moralidade deixará de ser um estudo prático e de ter qualquer tendência a regular nossas vidas e nossas ações”.
\end{abstract}

D. Hume. An enquiry concerning the principles of morals. 


\section{Introdução}

Este texto trata da relação entre crenças e emoções ligadas ao nosso agir moral, em particular nas situações dilemáticas. Penso que tal relação é bastante relevante para se tratar o intuicionismo e os dilemas morais. Esse trabalho busca enfocar a teoria intuicionista e o método do equilíbrio reflexivo quando aplicados ao estudo dos dilemas morais.

A teoria moral intuicionista contemporânea foi desenvolvida inicialmente por George E. Moore, e posteriormente foi sendo retomada e modificada por diferentes autores partindo de David Ross e, mais recentemente, por R. Audi e W. Sinnot-Armstrong, e na abordagem dos dilemas morais por B. Williams e C. Gowans. No entanto, Audi e SinnotArmstrong têm concebido as intuições associando-as ao estado mental de crenças. Williams reconheceu o papel que as emoções possuem, como, por exemplo, o arrependimento, no sentido de indicar os dilemas (conflitos de deveres) genuínos, uma vez que estamos sempre impossibilitados de chegar a uma alternativa moralmente aceitável sem permanecer com um sentimento que prossegue indefinidamente.

Gowans postulou a ideia de um intuicionismo reflexivo seguindo em parte essa trilha de Williams, mas afirmou que indicar o certo e o errado em situações de dilemas morais não depende apenas de nossas crenças morais, mas de valores que são atribuídos às relações que o sujeito tem com outras pessoas. Assim, costuma-se valorizar mais umas relações do que outras. Em caso de ter-se que tomar uma decisão moral em uma situação difícil como um dilema nas relações com pessoas que valorizamos muito, teremos que nos defrontar com um erro moral inevitável. Gowans incorpora um elemento reflexivo importante ao lado das emoções e crenças.

Minha proposta aqui seria de indicar que, por um lado, é plausível a descrição de Gowans, mas, por outro, acredito que estas intuições poderiam, diferentemente, ser entendidas como uma composição de crenças e emoções. Parece-me que uma boa ou má ação moral é indentificada por emoções como louvor ou elogio, culpa ou indignação, mas também por crenças do tipo matar é errado e mentir também.

Gostaria de me concentrar no possível papel das intuições nos dilemas morais. Este objetivo me dirige para uma questão de epistemologia e de psicologia morais no papel desempenhado pelas emoções nos dilemas. Com 
relação às emoções sabe-se que elas formam um estado mental entre os diferentes estados existentes (AUDI, 1999).

Posso afirmar que não há unanimidade na definição do que seria um dilema moral, mas uma definição bastante plausível seria aquela que afirma que ele é "uma situação (...) na qual um agente moralmente deve e pode fazer uma ação, e moralmente deve e pode fazer outra ação” (GOWANS, 1994, p. 47).

Para que se entenda isso um pouco melhor, pode-se apelar para uma classificação dos tipos de dilemas em três categorias. O solúvel ou aparente, ou seja, aquele no qual dois deveres conflitam, e há razões para agir conforme um ou conforme o outro dever. Os deveres, nesse caso, podem ser hierarquizados para que o agente decida com base na prioridade de importância dos dois deveres em conflito (McCONNELL, 1978, p. 271).

Em segundo lugar, alguns denominam o dilema insolúvel ou verdadeiro dilema, que seria visto mais como uma decorrência da vida, isto é, mesmo que o agente procure ser um homem bom, vê-se enredado em circunstâncias alheias que independeram de uma escolha pessoal anterior. Neste caso, também "Deve-se fazer x e deve-se fazer y, onde y é equivalente a não-x”. Isto é, ocorre a colisão de regras morais. Não é uma questão puramente lógica, mas existencial (TRIGG, 1971, p. 55).

Por vezes, aparece outra denominação (tipo), o dilema é chamado de genuíno. Esse configuraria uma situação na qual um agente deve fazer a e deve fazer $b$, mas não pode fazer ambas ao mesmo tempo (WILLIAMS, 1965). Sob essa denominação entende-se que nenhuma demanda moral pode ser mais "pesada" do que a outra. Brink afirma que o dilema genuíno é um dilema insolúvel de obrigações prima facie (BRINK, 1994, p. 218), ou seja, de obrigações intuitivamente assumidas por agentes como igualmente obrigatórias. Por exemplo, pode-se assumir que é uma obrigação prima facie ajudar o pai na velhice. Mas se uma pessoa cresceu em uma família, e esta mesma pessoa foi abandonada pelo pai durante a sua infância, ela poderia ficar primeiramente sem saber o que fazer, e ficar em um conflito prima facie entre ajudar ou não ajudar o pai. Refletindo melhor, o abandono do pai seria possível de fazê-la sentir-se justificada a não seguir a segunda obrigação ${ }^{1}$.

\footnotetext{
${ }^{1}$ A classificação apresentada acima não foi selecionada como resultado de uma análise comparativa de várias classificações possíveis, mas apenas a partir de como alguns autores conceituaram os dilemas. Pode-se identificar rapidamente que há uma sobreposição entre o que uns denominam dilemas insolúveis e outros de dilemas genuínos. A diferença entre eles está na ideia de que para os que usam a denominação de "insolúvel", o dilema decorre de uma contingência da vida, e não teria sido provocado
} 
Creio que se percebe que os estados mentais de crenças e emoções envolvidos nos dilemas são muito relevantes não só porque pode haver problemas conceituais relacionados a eles, mas porque as diferentes ciências têm avançado muito no conhecimento desses estados. Penso que a filosofia deve procurar acompanhar esses resultados. Primeiro, porque as pesquisas empíricas afirmam que a área emocional do cérebro é ativada antes da área das operações lógicas nas decisões morais. Além disso, o conhecimento de certos distúrbios emocionais como a depressão ou a sociopatia, ou cerebrais, como os psicopatas extremos, não se sensibilizam com os atos perversos ou violentos. Em segundo lugar, como consequência dessa primeira, faria mais sentido pensarmos na colaboração das duas áreas (a afetiva e a lógicoracional) para as decisões morais. Se esse conhecimento for desprezado, certas abordagens filosóficas ficarão sem sentido face a tal conhecimento.

Sendo assim penso que deveríamos rever as nossas concepções e categorias filosóficas sobre o processo de deliberação moral considerando esse novo conhecimento científico. Só a título de exemplo, qual o sentido na filosofia de se continuar falando de "vontade" ou "akrasia", se tivermos condições de descrever melhor os fenômenos que os gregos e os modernos atribuíam ao homem, utilizando-se dos conhecimentos científicos atuais da genética, da sociobiologia evolutiva, da psicologia cognitiva e do desenvolvimento, da psiquiatria e das neurociências? Evidentemente que a questão da justificação de nossas ações morais diz respeito também a questões que envolvem uma teoria geral da ação.

Uma teoria intuicionista da moral deveria tanto quanto possível estar acoplada aos conhecimentos científicos atuais.

\section{A importância das emoções para 0 entendimento dos dilemas morais}

Por que, então, as emoções (intuições) interessam à discussão sobre os dilemas morais? Porque a polarização indicada acima entre racionalistas e não-racionalistas demanda melhor entendimento do que se passa nos casos dilemáticos. A discussão levou a diferentes problemas, além dos lógicosemânticos. Gostaria de mencionar inicialmente três.

por uma situação na qual o próprio agente teria contribuído para acontecer. Santo Tomás e Kant, a propósito, admitiam que os dilemas são causados por deliberações anteriores erradas, conduzindo 0 agente a decisões insolúveis do ponto de vista moral. 
O primeiro problema me parece ser o metafísico, que nos conduz à pergunta sobre se os dilemas são fatos no mundo ou não. Houve uma polarização de posições sobre a existência ou não de dilemas. De um lado, colocaram-se os racionalistas e, de outro, os chamados sentimentalistas ${ }^{2}$. O primeiro grupo rejeita a existência dos dilemas morais genuínos, por duas razões: 1) duas obrigações opostas e simultâneas implicariam em uma inconsistência lógica e teórica; 2) acredita que o chamado "resquício emocional" (culpa, arrependimento ou remorso), pelo fato do agente não poder realizar uma das alternativas de ação, não torna o dilema insolúvel. Para este grupo, não é irracional decidir-se por uma das alternativas, quando não se pode realizá-las ao mesmo tempo.

Embora Williams afirme que o estado de aflição moral seja perene enquanto um resquício emocional do dilema genuíno e a marca distintiva entre um conflito de crenças e o conflito de desejos, penso que seria mais adequado admitir que o estado emocional gerado pela situação dilemática seria passageiro. Após a decisão, os sentimentos de remorso não fazem mais sentido, pelo fato da outra alternativa não ter sido realizada. Faz-se o que é possível.

O segundo grupo aceita a existência de dilemas morais genuínos e afirma que eles não só existem, como a opção por qualquer uma das alternativas implica em erro moral inevitável para o agente. Por isso o agente sentiria, de qualquer modo, arrependimento, remorso ou culpa após optar por qualquer alternativa de ação. Isso identifica uma situação insuperável. É como se fosse uma situação trágica da vida humana. As tragédias antigas já indicavam como certas circunstâncias ou ações que praticamos podem colocar-nos em situações bastante delicadas.

Se o que indica a existência de dilemas é a permanência de resquícios emocionais no agente, que podem ser reprimidos, mas jamais resolvidos, então os sentimentalistas têm razão, pois isso parece um fato da nossa existência. Mas por que tal fato justificaria que se permanecesse no estado emocional de arrependimento a vida toda?

A resposta a essa pergunta nos leva a dois outros problemas. Primeiro, o problema do conhecimento moral e de sua justificação, um problema epistemológico. Um racionalista e realista como Brink aceita a realidade dos dilemas como uma inconsistência lógica possível, mas para ele qualquer das duas

2 Sentimentalista está sendo usado aqui para indicar os filósofos que dão importância aos sentimentos (emoções) na descrição dos dilemas morais. 
justificações usadas pelo agente parece ser uma razão para agir moralmente, e não há motivo para se permanecer com o sentimento de arrependimento.

Por outro, se a resposta for que a deliberação é mais bem justificada por meio das intuições (emoção, como, p. ex., a compaixão), para um intuicionista então seria possível dizer que os sentimentos podem justificar nossas ações, e isso explica também por que a situação dilemática gera um estado subjetivo de aflição moral.

Para racionalistas como Kant, a justificação moral de uma máxima de ação não pode ser formulada utilizando-se fatores heterônomos à consciência individual como os sentimentos ou emoções. Contudo, não estaria o agente de fato moralmente orientado, se lançasse mão apenas de seu raciocínio prudencial ou então de suas intuições emocionais sobre a forma mais correta de agir? Além disso, por exemplo, uma pessoa que sentisse compaixão por certa pessoa e não por outras, porque estaria ela agindo imoralmente? Não quero reproduzir os argumentos que Kant usou para criticar essas visões. Fica a pergunta sobre qual a teoria que melhor definiria nosso modo de justificação moral?

Um terceiro campo de problemas diz respeito ao campo da psicologia moral. Houve psicólogos como Kohlberg que procuraram mostrar que a moralidade no homem se desenvolve até atingirmos um grau mais racional, bastante próximo do ideal kantiano de deliberação. Mas Kant foi demais exigente. Kohlberg foi questionado por Gilligan, que mostrou que a moralidade nos meninos e nas meninas se desenvolve de modo diferente. Nas meninas, principalmente, seu comportamento moral envolveria uma atividade de cuidado e não de seguir regras ${ }^{3}$. Se o cuidado tem bases afetivas e não racionais, como então reagiriam as meninas em situações dilemáticas? Como estaria melhor descrita nossa moralidade?

\section{0 intuicionismo moral empírico}

Volto à questão epistemológica com relação à justificação, mas também com relação ao tipo de conhecimento que é o moral. Mas por que a opção racionalista, então, ainda parece a muitas pessoas ser a posição adequada? A desvantagem do racionalismo é não reconhecer a importância de nossos sentimentos morais tanto no caso de que eles podem ajudar a tomar atitudes

\footnotetext{
3 Darlei Dall 'Agnol tem insistido que é importante fundir e conciliar as duas perspectivas em uma teoria do cuidado respeitoso. Mas não haveria de se buscar também uma base científica?
} 
morais, como justificá-las em certos casos, ou até caracterizar adequadamente a situação dilemática como fazem os sentimentalistas acima caracterizados.

Mas se o intuicionismo moral pode ser uma opção alternativa de justificação, não creio que o intuicionismo racionalista seria a melhor opção. Mas qual seria o tipo de intuicionismo? Seria ele um empírico? Teria um caráter reflexivo ou estaria baseado em intuições de caráter emocional?

Parece-me que afirmar que, diante de um dilema moral genuíno, considerando-se do ponto de vista descritivo, os agentes de fato vivenciam um estado de forte envolvimento emocional é algo bastante razoável. Nesse caso, poder-se-ia dizer que tal estado psicológico seria bastante compatível com uma justificação intuitiva, ou seja, que procuramos justificar nossas decisões em caso de dilemas com base em intuições sedimentadas na nossa moral cotidiana ou costumeira, não reflexiva, como definiu Dewey.

Mas parece igualmente óbvio que, se temos algum tempo para tomar a decisão, a reflexão entra em jogo já que, para atores morais com sensibilidade moral, a situação envolve uma decisão difícil.

O intuicionismo foi definido certa vez por Frankena, tal como desenvolveu-se no século 19 e primeira metade do século 20, "como aquela teoria moral que afirma que os valores morais e princípios básicos são intuitivos ou evidentes por si mesmos, prescindindo de uma justificação lógica ou psicológica" (FRANKENA, 1963, p. 122). Parece-me, entretanto, que Frankena estaria se referindo ao intuicionismo racional de Moore, Prichard e Ross.

Bem mais recentemente, Audi (2008) procurou caracterizar um outro tipo de intuicionismo, que poderia ser não só racional, mas também poderia ser pensado de modo empírico. Diferentemente de Ross, por exemplo, que professava que temos intuições intelectuais representadas na forma de deveres morais prima facie, Audi propõe-se a pensar uma epistemologia moral que também não seja fundacionalista como a de Ross que, para ele, não o era.

Nadelhofer (2010) afirma que Ross pretendia que, uma vez que se identificassem os deveres prima facie, uma indução intuitiva permitiria ao agente selecionar qual dever em um determinado contexto seria mais irrefutavelmente forte em relação aos outros (p. 310).

A proposta empirista de Audi indica que as intuições são respostas não inferenciais à experiência. Uma resposta não inferencial significa uma resposta que não é sustentada por nenhuma premissa anterior. Afirma que uma intuição é um estado psicológico como uma crença (AUDI, 1996, p. 109). A intuição, entretanto, também não é algo a priori. Audi afirma seguir 
Ross, para quem o intuicionismo moral não implicava em um racionalismo moral. A definição de intuição para Audi, embora ainda não seja bem precisa, pode ser comparada ao vulto de uma pessoa em um dia de cerração: não se tem clareza, mas sabe-se que é uma pessoa. Por fim, a intuição para Audi é algo pré-teórico, mas exige que se possa ter uma ideia do que se trata. Caso contrário, não seria possível ter uma ideia mínima do que é afirmado em uma proposição. Isso não significa sua infalibilidade. Caso haja, na visão de Audi, uma razão para abandonar aquela ideia expressa em uma proposição dever-se-á abandoná-la (AUDI, 1996, p. 110).

Audi faz questão de salientar que uma intuição também não é algo perceptualmente ótico. Por exemplo, os direitos não são visíveis, mas são intuitivos. Também não são teóricos, pois não dependem de teoria alguma (p. 112). As intuições podem ser resultado da reflexão a priori ou empírica, mas são sempre sobre casos e não são generalizações (AUDI, 1996, p. 113). Audi se estende um pouco mais na caracterização das intuições, mas creio que por ora esta ideia é suficiente para entender a sua definição.

Em função desta ideia como ficaria então o caso das emoções nas situações dilemáticas? Seria possível afirmar que as intuições geradas poderiam ser entendidas como crenças (intuições) resultantes de respostas a tais experiências? E será que as crenças não se relacionam com as emoções de modo que fossem resultado delas?

Suponha-se um caso bem genérico de um médico diretor de uma CTI superlotada em um hospital do SUS no Brasil. Ele deve decidir qual paciente entre dois vai ser acolhido. Já foram buscadas todas as opções de transferência de pacientes, e será possível acolher somente um deles. As alternativas são as seguintes: 1) um paciente bastante idoso e gravemente doente que precisaria de procedimentos de custo elevado com resultados pouco efetivos em termos de cura de sua doença; 2) dois acidentados em trânsito para atendimento de emergência, sendo uma criança e sua mãe.

Mesmo que o diretor desta CTI tenha de tomar uma decisão racional, ele não terá emoções que possam conduzi-lo a sentir compaixão do senhor idoso, e uma ansiedade tremenda para salvar primeiramente a criança? Penso que essas emoções viriam à mente de qualquer pessoa em nossa sociedade. Mas pode ser que um médico treinado possua outras emoções, ou talvez elas venham associadas a outros sentimentos também.

Intuitivamente me parece que no caso do exemplo há uma tendência a se optar por tentar salvar a criança e sua mãe primeiramente, pois talvez se 
possa resolver um dos outros casos ou os dois em lugar do primeiro paciente. É claro que poderíamos levantar outros problemas em relação ao caso.

Se as intuições são respostas não inferenciais à experiência, elas são manifestações de nossas emoções? Neste aspecto, Sinnot-Armstrong prefere falar explicitamente em "crenças morais" (moral believes) e não de intuições, embora defenda também uma posição intuicionista (SINNOTARMSTRONG; TIMMONS, 2006). Pensemos em outro exemplo: se alguém machucar um bebê e expressar alegria ao mesmo tempo, tal fato não geraria da parte de observadores um juízo moral negativo (indignação moral, p. ex.)? Parece-me bastante convincente a perspectiva de Audi.

Além da indignação (uma emoção), outras emoções poderiam desempenhar esse papel. P. F. Strawson (1974), denominou algumas das emoções morais de atitudes reativas, isto é, um conjunto de atitudes expressas por algumas emoções que representam uma reação do agente em relação a uma atitude de outro, as reações dos outros à atitude do agente, atitude ou uma reação do agente em relação a uma atitude sua (STRAWSON, 1974). Elas têm um papel de expressar o comportamento moral social de agentes morais uns em relação aos outros e de cada um para consigo mesmo.

Um aspecto importante, destacado por Strawson, é o fato de que as formas diferentes das atitudes reativas são conectadas humanamente e não logicamente. Elas assim devem ser vistas de três perspectivas: 1) as demandas que são feitas aos outros; 2) as reações dos indivíduos às possíveis ações injuriosas dos outros; e 3) as nossas autorreações associadas às demandas dos outros para conosco. Essas últimas, então, expressam o sentimento de uma pessoa ao estar comprometida ou obrigada (no sentido de obrigação) através do sentimento de culpa ou de remorso; ou finalmente de ser responsável, incluindo o fenômeno da vergonha ${ }^{4}$. "Em geral [afirma Strawson], embora dentro de limites, nós demandamos de umas pessoas para outras, tanto quanto de nós para os outros, aquilo que demandamos de outros para nós mesmos”. Por essa razão, para Strawson, essas três atitudes sempre estão juntas e "têm suas raízes comuns na nossa natureza e em nosso pertencimento a comunidades humanas".

Strawson introduz também o termo atitudes reativas pessoais. Estas "baseiam-se e refletem uma expectativa e uma demanda por algo; manifestação de certo grau de boa vontade ou atenção da parte de outros

\footnotetext{
${ }^{4}$ Não vou abordar o problema do solipsista moral (1962, p. 15), que é só uma possibilidade conceitual.
} 
seres humanos em relação a nós mesmos; ou pelo menos a expectativa de, e demanda por uma ausência de manifestação de uma vontade má (ill) ou desatenção indiferente (indifferent disregard)". Alguém poderia confundir as atitudes com juízos morais. Mas penso que os juízos têm base racional, enquanto as atitudes, ao contrário, repousam sobre sentimentos e, por isso, possuem bases emocionais ${ }^{5}$.

Strawson afirma que as atitudes reativas expressam nosso compromisso para com os outros. Esse compromisso, diz ele, "é parte de nosso quadro geral da vida humana, não algo que surge para uma revisão como os casos particulares que surgem para a revisão nesse quadro geral” (1974, p. 13). Além disso, ele escreve que dependemos desse compromisso na nossa vida ordinária de relacionamento com os outros (1974, p. 11). Ele perpassa eficazmente e está profundamente enraizado em nós, por isso, estar envolvido em relacionamentos pessoais significa justamente "estar exposto a essa variedade (range) de atitudes reativas e sentimentos (...)” (1974, p. 11).

As atitudes reativas são essencialmente reações às qualidades da vontade dos outros em relação a nós, manifestas nos seus comportamentos: se boa ou má vontade, ou indiferença, ou ausência de preocupação em relação a nós (Strawson, 1974, p.14). Assim, por exemplo, o ressentimento é uma reação à injúria ou indiferença praticada por outros a alguém ${ }^{6}$.

Por meio desses sentimentos o ser humano manifesta ao outro como ele interpreta a atitude do outro em relação a si e vice-versa. A identificação das atitudes reativas parece ser uma forma de se definir a responsabilidade sem precisar recorrer a termos como a liberdade e a consciência moral. Podese perfeitamente pensar que um indivíduo tem o sentimento de ressentimento em relação a uma ação que outro fez a ele. Analogamente, aquele que sente indignação e censura os atos de outro indivíduo, considera tais atos moralmente incorretos.

Entretanto, no contexto moral, não se deve esquecer também a função das atitudes objetivas. Elas têm um papel importante, uma vez que Strawson está

5 É importante lembrar, sobre isso, que as pesquisas realizadas nos anos 70 , pelo neurocientista Benjamim Libet coincidem com as intuições filosóficas de Strawson, ao afirmar que a decisão voluntária se daria, sem a contribuição da consciência que decide o resultado da ação, por meio de facilitações ou inibições. A consciência, para Libet, não daria início a ação voluntária. Além disso, na origem da intenção e da realização da ação há memória emocional, e essa não seria controlada pela consciência (MALDONATO, 2008, p. 91).

${ }^{6}$ Strawson, entretanto, alerta que há um aspecto enganador tanto no conceito de atitudes como na sua descrição, mas quer manter o nome pelo seu aspecto sugestivo. 
preocupado com as variações às quais as atitudes reativas estão submetidas (1974, p. 6-7). Na nossa vida cotidiana elas podem ser suspensas por atitudes objetivas. Suspende-se as atitudes reativas diante de determinados tipos de pessoas como as deficientes ou incapacitadas, pois estão impedidas de exercerem seu discernimento moral, por isso também merecem dos demais um olhar especial.

As modificações a que o ressentimento pode estar sujeito são divididas por Strawson em dois grupos: o primeiro grupo inclui desculpas como "não pretendia", "não havia me dado conta", "não sabia”, "não pude evitar", "tinha que fazer", "fui levado a”. Essas atitudes, no entanto, não podem fazer com que seja suspenso o sentimento de ressentimento, pois de modo algum fazem que o "agente seja um objeto inapropriado do tipo de demanda por boa vontade e por consideração que são refletidas em nossas atitudes reativas ordinárias” (1974, p. 7).

O segundo grupo é dividido em dois subgrupos. $\mathrm{O}$ primeiro subgrupo inclui desculpas do tipo "ele não era o mesmo", "ultimamente ele se encontra sob grande pressão", "estava sob hipnose". O segundo subgrupo diz respeito a desculpas do tipo "ele/ela é só uma criança", "é um esquizofrênico sem cura", "tem um comportamento compulsivo", "tem uma mente completamente pervertida”. Com relação ao primeiro subgrupo, as desculpas oferecidas pelo agente que causa o ressentimento não podem amenizar o sentimento da pessoa que sofreu as ações, portanto os sentimentos não estão fora daquilo que pode ser esperado pelas pessoas atingidas pelas ofensas em um contexto de relacionamento interpessoal. O ressentimento por parte daquela pessoa que sofreu a ação é perfeitamente adequado, não podendo ser suspenso nem no momento da ação, nem mesmo depois.

No segundo subgrupo, para Strawson, todas as nossas atitudes tendem a ser extremamente modificadas $(1974$, p. 8), pois os agentes são indivíduos com problemas e não tomados como "normais", porque ou apresentam deficiências (deformações e transtornos psíquicos) ou, ainda, são crianças. A atitude objetiva em relação a esse grupo de pessoas adotada por quem sofreu algum tipo de ofensa por parte dessas pessoas pode vir também acompanhada de outros sentimentos, mas não são os mesmos como o ressentimento, gratidão ou condenação moral; são atitudes de medo diante de um psicopata, repulsão diante de um indivíduo fisicamente deformado, compaixão diante de um deficiente ou mesmo amor.

O fato de desenvolvermos e suspendermos atitudes reativas para com os outros nas circunstâncias do segundo subgrupo do segundo grupo acima mencionado não impede que adotemos temporariamente atitudes objetivas 
para com adultos normais como uma espécie de refúgio ao envolvimento, ou em uma atitude de ajuda, ou mesmo em uma atitude de curiosidade intelectual em relação a outras pessoas. Mas sendo humanos, lembra Strawson, não podemos permanecer muito tempo nessa atitude de distanciamento. Percebe-se sempre que as pessoas vivem as experiências morais em uma tensão entre as atitudes reativas e as atitudes objetivas (1974, p. 10).

Novamente retorno a questão de saber se nossas intuições são crenças ou emoções. Pelo que desenvolveu Strawson, teríamos muitas evidências para acreditar que nossos julgamentos morais têm base emocional e não racional. Para Audi, a tarefa central da intuição seria fornecer conhecimento direto (não inferencial) ou crença justificada da verdade de proposições morais. Isto implica em pensar a natureza das intuições como auto-evidências. Audi classifica também dois tipos de auto-evidência: 1) proposições imediatamente auto-evidentes: são entendidas por "adultos normais" (Audi, 2008); 2) proposições mediatamente auto-evidentes: só entendidas pela reflexão. A importância do intuicionismo moral, na versão de Audi, radicaria então no fato de que ele considera importantes tais intuições auto-evidentes.

Mas se se aceitasse que crenças morais podem ter base em emoções como aversão à violência, uma pessoa poderia acreditar que lutas de boxe são moralmente condenáveis. Da mesma forma que sentimos aversão (repudiamos) às pessoas que maltratam crianças, e alguns de nossos sentimentos expressam nossas crenças morais, então acreditamos que os maus-tratos contra crianças são errados. Os sentimentos estão direcionados a algum conteúdo. Suponha-se que Maria está indignada com Suzana porque esta traiu sua confiança. O sentimento de indignação moral tem uma razão, e essa baseia-se na crença de que Suzana revelou um segredo sobre Maria a José, Carlos e João, que não poderia.

Ora, se as nossas aversões e simpatias têm pelo menos uma boa base biológico-evolutiva e bioquímica, uma teoria filosófica só pode fazer sentido se seus conceitos afinam-se, ou caso não puderem ser adequados, que possam ser discutidos nessa discordância. Ainda acho que o intuicionismo empírico tem problemas, se comparado com a descrição que Strawson faz de nossas atitudes morais, e com o fato de que talvez crenças e emoções morais não sejam tomadas separadamente. Se as emoções tem uma base bioquímica, como a relação descoberta entre a substância oxitocina (OXT) e a capacidade dos mamíferos terem atitudes de preocupação para com seus semelhantes, qual o papel que ainda tem a racionalidade na relação com as emoções? (CHURCHLAND, 2011). 
Audi afirmou que as intuições não excluem reflexão. Por isso sua visão é um aspecto relevante para entendermos a perspectiva do intuicionismo de Gowans na próxima secção.

\section{0 intuicionismo reflexivo de Gowans}

Pois bem, voltando à discussão dos dilemas, segundo Gowans (1994) o intuicionismo moral reflexivo é um método de abordagem dos dilemas morais para tratar questões relevantes. Seria essa a teoria modificada da noção de equilíbrio reflexivo de Rawls? Em que sentido?

Gowans afirma que nossas decisões morais em caso de dilemas não podem ser justificadas por um modelo baseado em leis ou princípios puramente racionais, por isso, rejeita os modelos racionalistas kantiano e utilitarista. Ele acredita que uma versão modificada do equilíbrio reflexivo de Rawls seria mais adequada. Embora o método do equilíbrio reflexivo de Rawls se comprometa com a ideia de que o dever tem prioridade sobre o bem, para Gowans (1994, p. 32; RAWLS, 1971) não há nada no seu método que obrigue a isto. Deste modo, pode-se usar o método para buscar coerência entre intuições morais plausíveis. O problema para Rawls seria nos explicar por que não existiriam dilemas morais.

Um método pode aceitar que, no caso de dilemas morais, devesse deixar de lado as inconsistências lógico-teóricas como uma questão a ser decidida e requerer, além disso, um plano coerente de ação (GOWANS, 1994, p. 34). O método também deve exigir mais das intuições normativas aceitas por Rawls para lidar com questões metaéticas; por exemplo, as de caráter linguístico e lógico. Ele também deveria abordar questões sobre a natureza da racionalidade prática e sobre a natureza da pessoa moral (GOWANS, 1994, p. 34).

Gowans aponta, corretamente, que Rawls exclui certos sentimentos importantes das capacidades morais relevantes dos indivíduos representativos na $\mathrm{PO}$, indicando apenas que pessoas devem ter o senso de justiça, porque caso contrário elas podem distorcer os julgamentos morais dos sujeitos hipoteticamente concebidos (GOWANS, 1994, p. 34; RAWLS, 1971, p. 4948). Deve-se acrescentar que Rawls na delimitação da PO também afirma que os sujeitos não podem sentir inveja, e devem viver em um tipo de sociedade com média escassez de bens. Caso contrário, seu experimento de pensamento implicaria, no caso de muita escassez, em uma disputa selvagem por alimentos, por exemplo, levando seu modelo a uma aproximação com a 
teoria hobbesiana. No caso de extrema abundância, creio que os indivíduos poderiam continuar vivendo sem necessidade de uma organização coletiva, pois nada os obrigaria a viver em grupos.

Rawls, parece-me, não especificou que outras características pessoais deveriam ser evitadas ou mitigadas na pessoa. Mas é possível supor que ele poderia ter imaginado que a pessoa fosse dotada de capacidades como a de ter atitudes reativas: culpa, remorso, arrependimento, indignação (Cf. STRAWSON, 1974).

Rawls pensou talvez que tais capacidades - poderíamos imaginarcomo as atitudes reativas, não ofereceriam uma operação correta de nossas capacidades morais. Ora, para Gowans um estado mental absolutamente livre de emoções é impossível (GOWANS, 1994, p. 35). Além disso, pode-se concordar com Gowans que há os sentimentos morais (por exemplo: compaixão e proteção-cuidado) que mais contribuem do que distorcem os julgamentos morais.

Neste sentido, se os psicopatas e sociopatas não são capazes desses sentimentos mencionados, nem de remorso, culpa ou arrependimento, embora possuam certos elementos que compõem o "carisma do sociopata" como ser espontâneo, divertido, sedutor além de outros modos de ser e ter sentimentos que são extremamente superficiais, também não são capazes de agir moralmente (Ver STOUT, 2010, p. 19). Enfim, de certo modo, Rawls explicitou pouco a psicologia moral dos sujeitos morais na $\mathrm{PO}$ como já foi indicado por outros autores.

Gowans defende que existem alguns conflitos morais, nos quais para qualquer alternativa de ação o erro moral é inevitável. Parte do exemplo de Billy no romance de H. Melville (Billy Budd, sailor). As intuições indicam a melhor alternativa de ação, considerando-se as responsabilidades que temos para com as outras pessoas.

O coerentismo epistêmico de Rawls estaria adequado se a realidade moral for constituída por nossas crenças morais (p. 37). O ceticismo moral, por isso, é falso, pois há algo a ser conhecido que se relaciona com a moralidade, e nós podemos atingir a capacidade de entender a moralidade. Já o fundacionalismo moral seria implausível porque afirma que crenças são justificáveis se e somente se elas são evidentes e certas. Para aceitar que os dilemas existem, embora o próprio Rawls não o endosse, tem-se que aceitar o realismo moral, pelo menos em princípio (p. 38). 
Além disso, Gowans modifica a maneira de identificar o dilema. Para ele, ao invés de trabalharmos com conflito de deveres morais, é melhor que se pense os dilemas a partir de nossas vinculações afetivas com os outros, de modo que um conflito moral seja entendido como aquela situação na qual o agente tem responsabilidade para com duas pessoas. O que está em jogo, para ele, portanto são vínculos afetivos e nossas relações de responsabilidade para com as pessoas com as quais estabelecemos esses vínculos, e não se nosso sistema de regras morais é consistente ou não.

Por isso, a resolução dos dilemas não envolve optar por diferentes regras que poderiam justificar minha opção de ação, mas envolve decidir sobre alternativas que envolvem afetividade e um valor moral que se atribuí a elas. Quanto mais comprometido afetivamente, mais me sinto responsável por tal pessoa. Isso implica em um vínculo emocional.

\section{Considerações críticas à Gowans e ao intuicionismo}

O intuicionismo foi e ainda é alvo de críticas. Gowans jamais afirmaria que todas as pessoas teriam sempre os mesmos sentimentos e reações em situações dilemáticas (1994, p. 100), mas concorda com a filósofa Philipa Foot, que afirma que a existência de sentimentos implicaria a verdade da proposição conectada com tal constatação. Isso significa que quando um agente sente arrependimento ou remorso em relação a uma decisão tomada isso significa: "É verdade que tomei uma decisão moralmente errada, pois poderia ter tomado outra decisão, logo agi imoralmente, mesmo agindo moralmente, por isso sinto arrependimento". Ora, isso não faz sentido, pois se agi moralmente, como posso simultaneamente acreditar que agi imoralmente. Por isso, essa visão de que o erro moral é inevitável é problemática.

De outro modo, Gowans sugere que o agente poderia se expressar dizendo: "Fiz o melhor que pude, pois qualquer coisa que fizesse implicaria em algo errado, também. O que fiz em si estava certo, mas fazendo o que fiz implicou em não fazer também outra coisa, a qual não estava ao meu alcance concomitantemente com a primeira”. Por isso, Gowans afirma que em alguns conflitos morais genuínos o arrependimento é um sentimento inescapável o qual nos informa que a alternativa escolhida pelo agente foi errada. Poderia ser objetado a essa conclusão o fato de o agente ter feito o que pôde, e isso foi moralmente correto, logo não há porque se arrepender.

Uma segunda crítica afirma que as intuições morais seriam falíveis, logo não podem justificar nossas ações. Mas o fato de que as intuições 
morais são falíveis não estabelece que elas não tenham nenhuma credibilidade (GOWANS, p. 39). Se os seres humanos têm capacidade para o entendimento moral, então é razoável que as intuições morais estejam relacionadas à verdade delas. Como se viu a partir da ideia de Audi, um intuicionismo empírico não implica em abrir mão da verdade de nossas crenças morais. Se nossas crenças são coerentes e se elas são conectadas com sentimentos que as expressam, então não há porque rejeitarmos a possibilidade de falar em um conhecimento moral.

A terceira crítica contra o intuicionismo afirma que o realismo no caso dos dilemas precisa ser endossado para responder ao cético quanto à pergunta pelo regresso justificacional. Essa posição seria contrária a uma teoria coerentista como a de Rawls.

Por fim, uma última crítica perguntaria a Gowans se o fato de o indivíduo sentir arrependimento não poderia ser uma falsa emoção, resultado de uma falsa crença de que ele poderia, de uma maneira mágica, tendo feito diferente do que fez, não teria errado e não estaria arrependido. Tome-se o exemplo do filho que se culpa pela morte do pai que apresentou a doença de Alzheimer, um problema grave de saúde que o levou à morte. Ele se sente culpado porque acha que poderia ter feito mais para prolongar a vida do pai, que por sua vez dependia de mais recursos. Nem mesmo todos os recursos financeiros e os melhores médicos do mundo poderiam curar o pai.

De modo um pouco semelhante, mesmo que a situação não seja dilemática, parece-me correto sentir indignação e repulsa por um amigo que falou mentiras a nosso respeito. Mas seria irracional continuar sentindo indignação em relação a tal amigo, após ele ter se retratado e pedido sinceras desculpas pelo que fez. Da mesma maneira, acontece com aquele que decide em uma situação dilemática.

Não creio que essa última crítica seja fácil de ser resolvida. Há algo nos nossos sentimentos que precisaria ser melhor esclarecido. Um desses é a falsa crença que pode nos levar a sentir sentimentos errados. Alguns sentimentos podem basear-se em ilusões. Por exemplo, uma pessoa é chamada para conversar com o chefe e ao entrar e sentar nota que sua cadeira é mais baixa que a dele. A partir disso, ela faz o seguinte raciocínio errado: ele me deu essa cadeira para me fazer sentir menos importante do que ele. Logo em 
seguida, o chefe passa a fazer vários elogios ao empregado, e lhe oferece um outro cargo que lhe propiciará um aumento salarial ${ }^{7}$.

Concluindo, creio que ainda que pareça interessante o intuicionismo reflexivo falta-lhe compreender melhor a relação entre as crenças e as emoções, porque as crenças poderiam ser vistas como elementos constitutivos das emoções, pois, como mencionei, algumas crenças falsas podem gerar também sentimentos ilusórios. Além disso, as crenças nos permitem identificar futuros sentimentos semelhantes em relação aos mesmos objetos ou situações. Por exemplo, uma pessoa que sempre sente medo ao ver uma cobra é porque acredita que ela é venenosa, e seu veneno pode ser fatal. Então, o medo da pessoa existe em função da crença. Pode-se supor também que esta pessoa, diante de outra cobra, ao saber que não é venenosa, pode acabar por dissipar seu medo.

Neste sentido, imagino que uma nova maneira de pesar os dilemas deve ser desenvolvida, de modo que o conhecimento científico atual possa nos ajudar a melhorar o tratamento da questão. Chamaria esse novo intuicionismo de naturalista.

\section{Intuicionismo naturalista}

Como certos sentimentos morais indicam certezas sobre comportamentos morais, a falta desses sentimentos indica uma carência de preocupação moral por parte do agente com os outros indivíduos e para consigo mesmo (Ver: STRAWSON, 1964; e TUGENDHAT, 2002).

Pergunto-me, então, se não seria plausível defender uma forma de cognitivismo (realista e naturalista), uma vez que as intuições morais empíricas (os sentimentos sinceros ou atitudes reativas) seriam fatos da nossa existência enquanto humanos biologicamente e culturalmente constituídos. Assim, me parece que nossos sentimentos poderiam ser identificados como propriedades naturais constitutivos de nossa espécie. Imagino-os de forma que não seriam puramente elementos de justificação de nosso agir, mas funcionariam igualmente como um fato, verdadeiro ou falso, nas nossas relações pessoais. Poder-se-ia dizer que tais sentimentos ou emoções são

\footnotetext{
7 Sinnot-Armstrong aponta três tipos de ilusões relacionadas as emoções: 1) as derivadas do contexto; 2) as generalizações e; 3 ) as heurísticas. No exemplo dado ficou caracterizado uma ilusão de contexto, pois o empregado toma a diferença de altura das cadeiras como um tipo de humilhação.
} 
intuições morais, que fazem parte da herança humana, não apenas no sentido que fazem parte da vida sociocultural, mas genética e evolutiva incorporada?

Uma resposta afirmativa a isso teria importância para que talvez num futuro próximo, nos seja possível implementar as atitudes morais não só educacionalmente, mas como certas qualidades genéticas desejáveis, e evitar o nascimento de indivíduos desprovidos de disposições genéticas apropriadas a uma vida moral, seja ela como for definida. Teríamos de pensar em traços genéticos que favorecessem uma espécie de moral enhancement.

Se esses sentimentos morais são básicos para a existência de uma sociedade, então por que não garantir que todos os seres humanos possam nascer com predisposição genética para eles?

\section{Conclusão}

Seria prematuro tirar destas ideias conclusões mais perenes. Parece-me que, após tais considerações, seria possível retomar alguns pontos do que quis apontar.

Parece-me cada vez mais importante reconhecer certos fatos de nosso comportamento moral natural. Este entendido como aquele oferecido pelos dados científicos ou pela nossa experiência cotidiana na vida social e na relação com os outros seres vivos e com a natureza.

Quanto à justificação moral no caso dos dilemas, mesmo que os racionalistas afirmem que o resquício afetivo não implica em que algo ruim de fato aconteceu como resultado de nossa opção por uma das duas alternativas do comflito, creio, concordando com Gowans, que para alguns casos a opção por uma das alternativas, e o resultado afetivo específico, não nos livra do arrependimento de que mesmo assim erramos. Mas isso tem de ser melhor investigado.

Neste sentido, para encerrar, lembraria do filme "Truman's Show" no qual, sem saber que estava em uma realidade fictícia, o jovem Truman é induzido a ficar com um trauma emocional de medo do mar em razão da morte de seu pai. Um sentimento criado a partir de uma falsa crença.

\section{Referências bibliográficas}

AUDI, R. Intuicionism, Pluralism and the Foundations of Ethics. In: SINNOTARMSTRONG, W.; TIMMONS, M. Moral Knowledge? New readings in moral epistemology. (2o ed.). New York: Oxford, 1996. Moral Value and Human Diversity. New York: Oxford University Press, 2008. 
BRINK, D. "Moral Conflict and Its Structure". The Philosophical Review, 103, 1994: 215-247.

FRANKENA, W. Ética. Rio de Janeiro: Zahar, 1963.

GOWANS, C. Innocence Lost: An examination of inescaple moral wrongdoing. New York: Oxford University Press, 1994.

(Ed.). Moral Dilemmas. New York: Oxford University Press, 1987.

McCONNEL, T. "Moral Dilemmas and Consistency in Ethics". Canadian Journal of Philosophy, 8, 1978: 269-287.

MALDONATO, M. "Rumo a uma Ciência do Livre-Arbítrio. Scientific American. Brasil. v. 6, n. 76, 2008: 88-95.

MASLIN, T. K. Introdução à Filosofia da Mente. Porto Alegre: Artmed, 2009.

MELVILLE, H. Billy Budd, Marinheiro. Porto Alegre: L\&PM, 2005.

NADELHOFER, T.; NAHMIAS, E.; NICHOLS, S. Moral Psychology: historical and contemporary readings. Oxford: Blackwell, 2010.

NAPOLI, R. B. "Livre-arbítrio e responsabilidade a naturalização da responsabilidade de P. F. Strawson”. Ethica (UFSC), v. 8, 2009: 73-88.

RAWLS, J. A Theory of Justice. Cambridge, Mass.: Harvard University Press, 1971. . Justice as Fairness. Cambridge, Mass.: Harvard University Press,

2003.

SINNOT-ARMSTRONG, W. Moral Dilemmas. Oxford: Blackwell, 1988.

SINNOT-ARMSTRONG, W.; TIMMONS, M. Moral Knowledge? New readings in moral epistemology. ( $2^{\circ}$ ed.). New York: Oxford University Press, 1996.

STOUT, M. Meu Vizinho é um Psicopata. Rio de Janeiro: Sextante, 2010.

STRAWSON, P. F. "Freedom and Resentment". In: Idem. Freedom and Resentment. USA: Methuen, 1974. . Análise e Metafísica. São Paulo: Discurso Editorial, 2002.

TRIGG, R. "Moral Conflict". Mind, 80, 1971: 41-55.

TUGENDHAT, E. Lições sobre Ética. Petrópolis: Vozes, 1998.

. "Como devemos entender a moral". In: Idem. Não Somos de Arame

Rígido. Canoas (RS): Ed. da Ulbra, 2002, p. 25-50.

WILLIAMS, B. "Ethical Consistency". Proceedings of the Aristotelian Society, 39, 1965: 103-124.

WILSON, J. Q. The Moral Sense (2oe.). New York: The Free Press, 1995. 